\title{
High rate of prey consumption in a small predatory fish on coral reefs
}

\author{
W. E. Feeney • O. M. Lönnstedt • Y. Bosiger • \\ J. Martin · G. P. Jones · R. J. Rowe • \\ M. I. McCormick
}

Received: 2 June 2011/ Accepted: 14 February 2012

(C) Springer-Verlag 2012

\begin{abstract}
Small piscivores are regarded as important regulators of the composition of coral reef fish communities, but few studies have investigated their predatory ecology or impact on assemblages of juvenile fishes. This study investigated the foraging ecology of a common coral reef predator, the dottyback Pseudochromis fuscus, using underwater focal animal observations. Observations were conducted at two times of year: the summer, when recruit fishes were an available food item and winter, when remaining juveniles had outgrown vulnerability to $P$. fuscus. During the summer, P. fuscus directed $76 \%$ of its strikes at invertebrates and $24 \%$ at recruiting juvenile
\end{abstract}

Communicated by Biology Editor Dr. Stephen Swearer

Electronic supplementary material The online version of this article (doi:10.1007/s00338-012-0894-z) contains supplementary material, which is available to authorized users.

\section{W. E. Feeney}

Evolution, Ecology and Genetics, Research School of Biology,

Australian National University, Canberra, ACT 0200, Australia

W. E. Feeney · O. M. Lönnstedt · Y. Bosiger ·

G. P. Jones - R. J. Rowe - M. I. McCormick

School of Marine and Tropical Biology, James Cook University,

Townsville, QLD 4811, Australia

W. E. Feeney · O. M. Lönnstedt · Y. Bosiger ·

G. P. Jones · M. I. McCormick ( $\square)$

ARC Centre of Excellence for Coral Reef Studies,

James Cook University, Townsville, QLD 4811, Australia

e-mail: mark.mccormick@jcu.edu.au

J. Martin

Department of Resources-Fisheries, Berrimah, NT 0828,

Australia fishes. When striking at fishes, P. fuscus exhibited two distinct feeding modes: an ambush (26\% successful) and a pursuit mode (5\% successful). Predator activity in the field peaked at midday, averaging 2.5 captures $\mathrm{h}^{-1}$ of juvenile fishes. Monitoring of activity and foraging in the laboratory over 24-h periods found that $P$. fuscus was a diurnal predator and was active for $13 \mathrm{~h} \mathrm{~d}^{-1}$ during the summer. The number of hours during which foraging was recorded differed greatly among individuals $(n=10)$, ranging from 4 to $13 \mathrm{~h}$. The number of predatory strikes did not increase with standard length, but the success rate and consumption rate of juvenile fishes did increase with size. Estimated hourly mortality on juvenile fish ranged from 0.49 fish $^{-1}$ in small $P$. fuscus individuals (30-39 $\mathrm{mm}$ standard length, SL; equating to 6.3 per $13 \mathrm{~h}$ day) to $2.4 \mathrm{fish} \mathrm{h}^{-1}$ in large $P$. fuscus individuals (55-65 mm SL; 30.6 per $13 \mathrm{~h}$ day). During the winter, $P$. fuscus struck at invertebrates with a similar rate to the summer period. These observations of the predatory ecology of $P$. fuscus support the hypothesis that in coral reef systems, small piscivores, because of their high metabolism and activity, are probably important regulators of coral reef fish community composition.

Keywords Predation - Coral reef fishes - Mesopredator . Recruitment · Piscivore - Digestion rate

\section{Introduction}

Predation is a fundamental driver of many patterns in ecological and evolutionary time (Lima and Dill 1990; Verdolin 2006; Johnson and Hixon 2011). The activity of predators influences many aspects of the ecology of prey populations including abundance patterns (e.g. Almany 2004; Berger and Gese 2007; McCormick and Meekan 
2007; White et al. 2010), activity schedules (e.g. Mukherjee et al. 2009; Strobbe et al. 2011), species composition (e.g. Almany et al. 2007; Stallings 2009) and the distribution of phenotypic characters (e.g. O'Steen et al. 2002; Fuiman et al. 2006; Gagliano et al. 2007; Holmes and McCormick 2009; Johnson and Hixon 2010). The dramatic reduction in the numbers of apex predators in most systems globally has encouraged researchers to investigate the role of predators in determining and regulating the composition and function of communities (Frank et al. 2005; Myers et al. 2007; Estes et al. 2011). It is well established that apex predators are important components of stable 'topdown' ecological systems (Myers et al. 2007; Estes et al. 2011). However, not all predators are apex predators, and in most systems, there is a lack of information on the direct and indirect roles that smaller predators play in influencing ecosystem processes necessary to parameterise ecosystem models.

Recent studies have found that these smaller, more abundant predators are important elements of stable and diverse ecological systems (Finke and Denno 2004; Navarrete and Berlow 2006; Elmhagen and Rushton 2007). In coral reef systems, the importance of small predators of juvenile fishes is universally acknowledged (Carr and Hixon 1995; Holbrook and Schmitt 2002; Holmes and McCormick 2010; Beukers-Stewart et al. 2011). Predatordriven mortality in naïve post-settlement fishes produces an exponential mortality schedule, which can result in over $60 \%$ loss of a cohort within $48 \mathrm{~h}$ of settlement (Doherty et al. 2004; McCormick and Hoey 2004; Almany and Webster 2006). These high mortality rates are largely attributed to small predatory fishes, making these fishes a primary influence over community composition (Connell 1998; Holbrook and Schmitt 2002; Holmes and McCormick 2010). Despite the ecological significance, few studies have examined the feeding ecologies of non-apex predators (but see Sweatman 1984; Beukers-Stewart and Jones 2004; Stallings 2009; Côté and Maljković 2010), making their potential impact on coral reef fish assemblages difficult to assess.

A common and important predator of juvenile coral reef fishes is the dottyback, Pseudochromis fuscus (Beukers and Jones 1997; Holmes and McCormick 2010). P. fuscus is widely distributed throughout the Indo-Pacific, extending from Japan in the north, Sri Lanka to the west, Vanuatu to the east and the southern Great Barrier Reef to the south (Gill 2004). It is gape limited, mobile and active (Munday et al. 2003; Holmes and McCormick 2010), with two genetically identical colour morphs whose function has been attributed to predatory mimicry towards similarly coloured juvenile damselfishes (Pomacentridae) (Munday et al. 2003; Messmer et al. 2005). On some tropical reefs, $P$. fuscus can comprise up to $10 \%$ of the total number of piscivorous fishes in the coral reef assemblage (Stewart and Jones 2001).

The present study investigated the predatory ecology of $P$. fuscus, including diet, foraging behaviour and success in order to determine the potential impact that this common small predator has on juvenile reef fish assemblages. The specific goals were (1) to determine the diet of $P$. fuscus of different sizes; (2) to examine the extent to which $P$. fuscus was a piscivore, and how foraging changed through the year; (3) to document the relative deployment and strike success rate of the different feeding modes used by $P$. fuscus to capture juvenile fishes; (4) to assess whether strike rate and success rate varied with size in P. fuscus; (5) to investigate whether $P$. fuscus displayed diurnal variation in predatory activity; (6) to determine the digestion rate of juvenile fishes by $P$. fuscus; and finally, (7) to estimate the potential daily consumption of juvenile fish by $P$. fuscus using information from aims 3 to 5 .

\section{Materials and methods}

Study site and sampling for stomach contents

All data were obtained at Lizard Island $\left(14^{\circ} 40^{\prime} \mathrm{S}, 145^{\circ} 27^{\prime} \mathrm{E}\right)$, northern Great Barrier Reef, Australia. Fishes typically recruit at this location during the summer (October through to February). Fifty-six P. fuscus (39-82 mm total length, TL) were collected from the shallow fringing reef around Lizard Island in December 1994 using a solution of the anaesthetic quinaldine and ethanol and a hand net. Fish were euthanized by pithing, and their gut cavities were injected with $10 \%$ formalin. In the laboratory, the gut was removed from the preserved alimentary tracts and contents identified to a broad taxonomic level.

\section{Field behavioural observations}

Behavioural observations were conducted on the shallow reef (2-4 m) surrounding Lizard Island in December 2009 (fish recruitment season; $26.2-29.5^{\circ} \mathrm{C}$ ) and August 2010 (non-recruitment season; $23.3-26.7^{\circ} \mathrm{C}$ ). During the recruitment period, 20 individual $P$. fuscus (10 yellow and 10 brown colour morphs) were observed for periods ranging from 55 to $75 \mathrm{~min}$ (mean $\pm \mathrm{SE}=61.65 \pm 1.06 \mathrm{~min}$, total 1,233 min). Due to logistical constraints, observations were performed between 0800 and 1700 hours. During the sampling episode in the non-recruitment period, 30-min observations were undertaken on 26 P. fuscus (13 of each colour morph). On entering a study site, a detailed search of the habitat was undertaken, and the first $P$. fuscus located was observed at a minimum distance of $2 \mathrm{~m}$ (similarly to Côté and Maljković 2010). This distance caused no apparent 
distress to the fish, and fish appeared to behave normally (as per Sweatman 1984). As these fish are territorial, the same site was not visited more than once to maintain replicate independence. The total length and standard length (TL and SL) of each fish were estimated by noting the position of the tip of the snout, end of the hyural plate and the end of the caudal fin relative to points on the substratum and then measuring these to the nearest $5 \mathrm{~mm}$.

For each focal individual, observers noted the behaviour and predatory ecology of $P$. fuscus. All strikes and their success were recorded together with the prey type they were directed towards. Strikes directed at substratum were classed as being directed towards invertebrates. Algae was never observed in gut samples, but rather small crustaceans, molluscs and fishes (see gut data below). Preliminary observations found that two distinct feeding modes were used when striking at juvenile fishes: ambush and pursuit feeding modes. Ambush feeding strikes were defined as feeding strikes directed towards a recruit fish where it was obvious to the observer that the recruit was not aware of the attacker's location prior to the feeding strike. Pursuit feeding strikes were defined as feeding strikes directed towards a recruit fish where it was obvious to the observer that the recruit was aware of the location of the predator prior to the feeding strike. If the $P$. fuscus had a juvenile fish in its mouth, or if the juvenile fish was chased into a rock crevice and it did not emerge within $3 \mathrm{~min}$, the attack was considered successful (as per Sweatman 1984). The latter represented about 5\% of strikes that were recorded as successful.

To enable the examination of the diurnal variation of strike rate at fish and success for $P$. fuscus, the field observations were undertaken over three time periods during the recruitment sampling period: morning (0800-1100 hours; $n=6)$, midday (1100-1400 hours; $n=6$ ) and afternoon (1400-1700 hours; $n=8$ ). To examine whether size influenced strike success, individuals were separated into 3 size classes: small (30-39 mm SL; $n=6$ ), medium (40-54 mm $\mathrm{SL} ; n=6)$ and large (55-65 $\mathrm{mm} \mathrm{SL} ; n=8)$.

\section{Laboratory observations of diel activity patterns}

Ten $P$. fuscus were captured using an anaesthetic clove oil/ alcohol/saltwater solution and a hand net on SCUBA around Lizard Island during March 2011. Following capture, individuals were transported to the research station and placed into 16- $\mathrm{L}$ aquaria to acclimate for a minimum of $24 \mathrm{~h}$. While acclimating, fish were fed bait squid once daily at a random time.

Observation filming was conducted in a purpose-designed 18-L PVC predator-prey tanks $(19.5 \times 65 \times 17.5 \mathrm{~cm})$, with a $7.5-\mathrm{L}(9.5 \times 65 \times 17.5 \mathrm{~cm})$ predator compartment and $6-, 1.5-\mathrm{L}(10.8 \times 10 \times 17.7 \mathrm{~cm})$ prey compartments
(Pomacentridae). Compartments were separated by Perspex to allow predators and prey to observe each other without physical interaction and had a 2-cm layer of sand on the bottom. Each predator compartment had a one plastic tube ( $\sim 12 \mathrm{~cm}$ long $\times 4 \mathrm{~cm}$ diameter) placed in the centre of the compartment to provide shelter. A small Pocillopora hard coral (approximately $3 \times 3 \times 4 \mathrm{~cm}$ ) was placed at the back of each prey compartment to create a shelter for prey. To ensure that predators received both visual and olfactory cues of prey, a 32-L header tank containing 20 prey fish (Pomacentridae) delivered aerated seawater into the predator-prey tank. Predator-prey tanks were situated outside to insure that predators could access all potentially necessary temporal cues (e.g. sun position, temperature). Sunrise and sunset were at approximately 0620 and 1830 hours, respectively. Water temperature within the aquaria averaged $28.2^{\circ} \mathrm{C}$ over the study period.

One $P$. fuscus was transferred to the predator chamber, and 2 prey (recruit damselfish) were transferred to each prey chamber $24 \mathrm{~h}$ prior to the start of filming. Each $P$. fuscus was filmed for $24 \mathrm{~h}$ using a digital colour infrared camera. $P$. fuscus were fed prior to transfer to the predatorprey tank but not during experimentation (48 h) to control for feeding associated variations in behaviour. Predators were released into predator-prey tanks at one of two different times of the day (1030 hours or 1600 hours). Predators were thus at their maximum hunger level at one of two different times. Prey fish in prey compartments and in the header tank were fed Artemia twice daily, and care was taken to randomise feeding times to ensure that increased predator activity was not due to the feeding of prey. The activity schedule of $P$. fuscus over a 24 -h period was measured from the videos by assessing activity in a 10-min block per hour. Preliminary investigation suggested that 10 min gave an accurate representation of activity rates in a 1-h period. Activity rates were then extrapolated to estimate total activity during each 1 -h period. Foraging rate and activity level were recorded for $P$. fuscus throughout the $24-\mathrm{h}$ period. Foraging rate was recorded as the total number of strikes at prey compartments per time period. A predatory strike was distinguished from normal motion by speed (movement greater than 2.5 body lengths per second) together with a noticeable C- or S-start (Domenici and Blake 1997). Activity was recorded as the time spent swimming.

\section{Digestion rate}

Eleven $P$. fuscus were captured using a quinaldine/alcohol anaesthetic solution and a hand net off the reef flat surrounding Lizard Island during December 1994 (mean length $=51.42$, range 36-67.5 mm SL). Individuals were transferred to separate aquaria with flow-through seawater 
Table 1 Description of index used to categorise levels of digestion for Pseudochromis fuscus

\begin{tabular}{|c|c|}
\hline $\begin{array}{l}\text { Digestion } \\
\text { category }\end{array}$ & Description \\
\hline 1. Fresh & Little or no digestion, apparently recently ingested \\
\hline $\begin{array}{l}\text { 2. Minor } \\
\text { digestion }\end{array}$ & $\begin{array}{l}\text { Superficial surfaces digested. Length } \\
\text { measurements of prey possible }\end{array}$ \\
\hline $\begin{array}{l}\text { 3. Moderate } \\
\text { digestion }\end{array}$ & $\begin{array}{l}\text { Body mostly digested, flesh showing myomeres. } \\
\text { Length measurement possible only as estimate }\end{array}$ \\
\hline $\begin{array}{l}\text { 4. Major } \\
\text { digestion }\end{array}$ & Body broken down into pieces of bone and flesh \\
\hline $\begin{array}{l}\text { 5. Advanced } \\
\text { digestion }\end{array}$ & $\begin{array}{l}\text { Some hard structures and small fragments of flesh } \\
\text { only }\end{array}$ \\
\hline $\begin{array}{l}\text { 6. Stomach } \\
\text { empty }\end{array}$ & Stomach lining clean or containing mucus only \\
\hline
\end{tabular}

(at $28^{\circ} \mathrm{C}$ ) and shelter and allowed to acclimate and evacuate their guts for $12 \mathrm{~h}$. Fish were then given a live or recently euthanized recruit damselfish (Dischistodus perspicillatus, Pomacentrus coelestis or Pomacentrus wardi; mean size $13 \mathrm{~mm} \mathrm{SL}$ ) as their only prey. The time of feeding was recorded, and the $P$. fuscus were killed at various time intervals after feeding $(0.5 \mathrm{~h} n=3,1 \mathrm{~h}$ $n=3,2 \mathrm{~h} n=3,4 \mathrm{~h} n=2)$. The stomach contents were dissected out, and fish prey assigned to one of 6 digestion categories, ranging from fresh remains (category 1) to an empty stomach (category 6) (Table 1).

\section{Statistical analysis}

To test whether the strike rate (per hour) at invertebrates and total number of strikes were similar between recruitment and non-recruitment sampling periods, two one-factor ANOVAs were conducted. One fish during the recruitment season that had a bite rate at invertebrates much higher than the rest (143 strikes $\mathrm{h}^{-1}$ ) was excluded from these analyses as a statistical outlier (Grub's test, $p<0.05$ ). This fish was not excluded from other analyses that did not involve this variable because of the small dataset. To investigate whether strike rate and capture rate differed between ambush and pursuit feeding modes, paired t-tests were used. Unequal variances between the feeding modes for capture rate necessitated the use of a Sign test. We used one-factor ANOVA to test whether strike and success rates of $P$. fuscus for juvenile fish were influenced by time of day (morning, midday and afternoon) or predator size (small, medium and large). The nature of significant differences found for time of day and size were further examined with Tukey's HSD means comparison tests. To investigate whether hourly capture, strike rates and capture rate differed between the two colour morphs of P. fuscus onefactor ANOVA was also employed. Digestion rate was analysed using regression analysis. The assumptions of homogeneity of variance and normality were examined by residual analysis.

Hourly consumption of juvenile fishes by $P$. fuscus was calculated as the mean of the hourly rates of successful strikes of the 20 observed individuals during the recruitment sampling period. Strike success rate was calculated for individual $P$. fuscus as the number of successful strikes divided by the total number of strikes within the observation period standardised to $1 \mathrm{~h}$. Mean strike success rate was the arithmetic average of the individual strike success rates. To calculate an estimated daily consumption on juvenile fishes, differences in strike success with time of day were taken into account. Overall, daily capture estimates were calculated for three foraging day lengths: $13 \mathrm{~h}$ (representing total daylight hours in December 2009: sunrise 0545 hours, sunset 1845 hours; the three time intervals used for calculation being 0645-1100 hours; 1100-1400 hours; 1400-1845 hours); $4 \mathrm{~h}$ (representing the minimum number of hours one laboratory fish was found to strike; allocated for calculation as 3-h midday and 1-h afternoon); $9.7 \mathrm{~h}$ (the mean number of hours laboratory fish was found to strike; allocated for calculation as 3.35-h morning, 3-h midday and 3.35-h afternoon). For daily consumption estimates, 95\% confidence limits (CL) were determined by summing the variances of the three time periods (morning, midday and evening), calculating a standard error and multiplying this with a Student's $t$ value at $n-1$ degrees of freedom.

\section{Results}

\section{Diet of Pseudochromis fuscus}

Of the 52 fish that contained food items (4 were empty), $25.0 \%$ contained fish tissue, $32.7 \%$ fish scales, $84.6 \%$ contained crustacean remains (including $9.6 \%$ that contained crabs) and $7.7 \%$ contained molluscs. This confirmed that $P$. fuscus primarily feeds crustaceans and small fishes. The smallest $P$. fuscus found to have remnants of fish (scales) in its guts was $36 \mathrm{~mm} \mathrm{SL}$, though only 3 fish were sampled that were smaller than this fish.

\section{Seasonal patterns of foraging}

During the recruitment period, an average of $23.7 \%$ of strikes (range, 0-19.4 $\mathrm{h}^{-1}$; mean, $10.5 \mathrm{~h}^{-1}$ ) was directed to juvenile fishes ( 216 of 912 strikes in $20.5 \mathrm{~h}$ of observation). During the non-recruitment period, $99.4 \%$ of strikes were made at invertebrates on the substratum. The remaining 2 strikes out of 364 strikes over a 13-h total observation period were made at recruit damselfish. P. fuscus made significantly more total strikes per hour in the recruitment periods than in nonrecruitment periods $\left(F_{1,43}=7.96, p=0.007\right)$, but there was 
no difference in the number of strikes directed to invertebrates between periods $\left(F_{1,43}=0.026, p=0.873\right.$; mean, 27.85 and $28.52 \mathrm{~h}^{-1}$ for non-recruitment and recruitment periods, respectively). During the recruitment period, capture rate and strike rate per hour and success rate per strike did not differ between the colour morphs $\left(F_{1,18}=0.114\right.$, $p=0.739 ; \quad F_{1,18}=0.044, \quad p=0.837 ; \quad F_{1,18}=0.0013$, $p=0.971 . n=10$ yellow and 10 brown, respectively).

Feeding modes

During all observation periods, each individual $P$. fuscus continuously patrolled the area within its home range. In the recruitment period, $P$. fuscus regularly moved between, and spent time around, areas of high juvenile fish abundance (primarily damselfishes). Upon arrival in an area of high recruit fish abundance, $P$. fuscus observed the local recruit population with minimal disturbance. When possible, it made a strike at a fish that appeared unaware of its location (ambush strike). When the local juvenile fish population was aware of its location, either a predatory pursuit ensued (pursuit strike) or no strike was made, after which the $P$. fuscus resumed patrolling its home range. Periodically, the fish stopped patrolling and made several feeding strikes towards the substratum (presumably invertebrates on sand, live coral, coral rubble or in the water column) and then resumed its patrolling behaviour.

Pursuit feeding strikes occurred more often than ambush feeding attempts $\left(t_{1,19}=-5.18, \quad p<0.001\right.$; Fig. 1a). Ambush feeding strikes were found to have significantly higher success rates per attempt than pursuit feeding attempts (26 vs $5 \%$; sign test, $Z=2.07, p=0.03$; Fig. 1b), but no significant difference was found in the overall captures per hour on juvenile reef fishes between the two feeding modes $\left(t_{1,19}=2.00, p=0.06\right.$; Fig. $\left.1 \mathrm{c}\right)$.

Field observations of diurnal activity patterns

Strike rate and the number of successful strikes on juvenile fishes differed with time of day. Strike rate per hour was highest in the midday period and lower in morning and afternoon periods $\left(F_{2,17}=4.07, p=0.04\right.$; Fig. $\left.2 \mathrm{a}\right)$. This trend was emphasised in the captures per hour, with the highest numbers of successful strikes per hour occurring around midday $\left(2.5 \mathrm{~h}^{-1} ; F_{2,17}=3.91, p=0.04\right.$; Fig. $\left.2 \mathrm{c}\right)$. The proportion of successful strikes per hour did not differ significantly with time of day $\left(F_{2,17}=0.363, p=0.70\right.$; Fig. $\left.2 b\right)$, although mirrored a similar trend to the other variables.

Laboratory observations of diel activity patterns

Laboratory observations over 24 -h periods indicated that $P$. fuscus was a diurnally active predator. The distribution of the proportion of the observation hour spent moving was
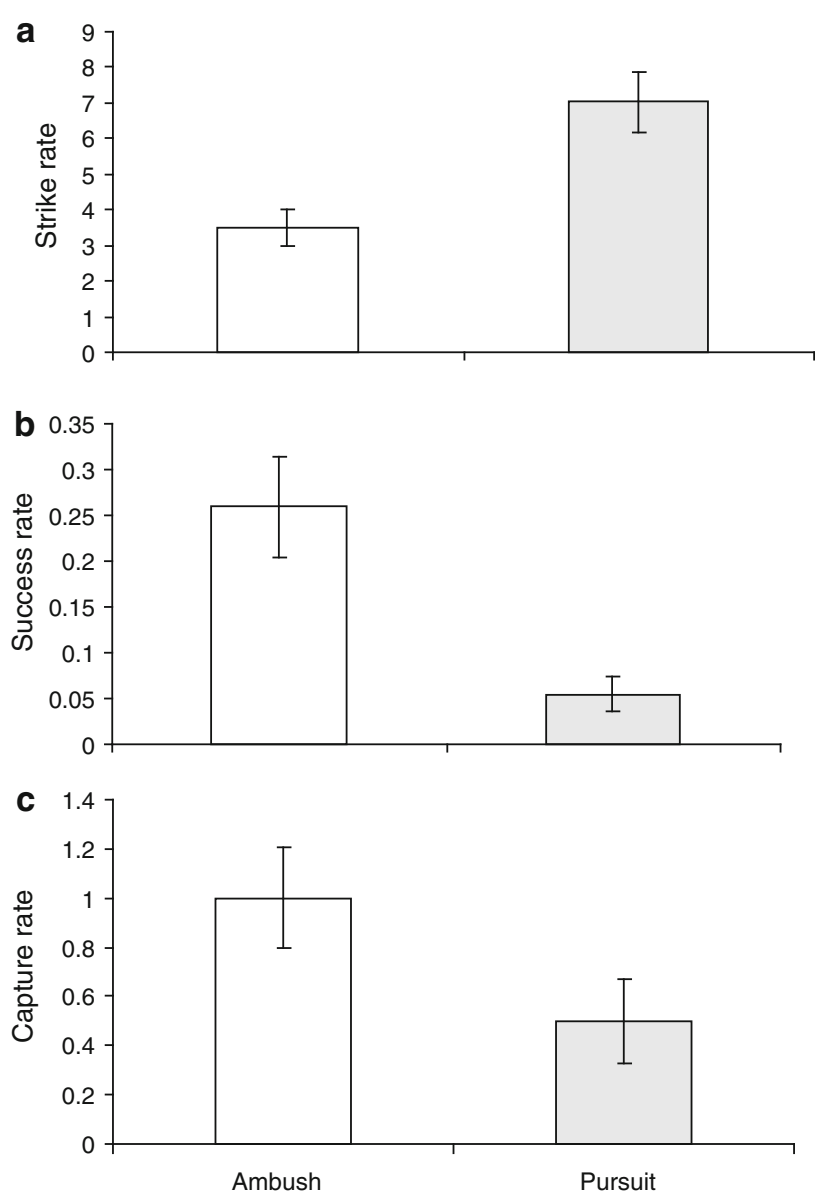

Fig. 1 Comparison of two feeding strategies displayed by Pseudochromis fuscus towards juvenile reef fishes (per hour; $n=20$ ). a Number of strikes; $\mathbf{b}$ success per strike; $\mathbf{c}$ total number of juvenile fishes captured per hour. Means with standard errors are shown

platykurtic with an average of $70 \%$ of the time spent moving during daylight hours (Fig. 3a). Eight P. fuscus out of 10 showed some swimming activity for $13 \mathrm{~h}$, with the remaining two were active for 15 and $22 \mathrm{~h}$. Mean strike rate showed little pattern within daylight hours given the high levels of variability among individuals (Fig. 3b). Individual fish showed markedly different periodicities in strike rate throughout daylight hours (Fig. 4), ranging from a bimodal signature of being most actively striking in the early morning and evening (Fig. 4a), through to being active for a very restricted period of time around midday (Fig. 4b). Four fish struck at prey in 12 of the 13 h of daylight, 2 fish struck in 4 of the daylight hours, while one fish struck over each of 13, 11, 10 and $7 \mathrm{~h}$ of daylight (mean number hours over a 24-h period in which strikes occurred $=9.7 \mathrm{~h}$ ).

Influence of size on strike rate

Predator size class did not significantly affect $P$. fuscus strike rate on small fishes $\left(F_{2,17}=0.96, p=0.40\right.$; Fig. 5a), with 

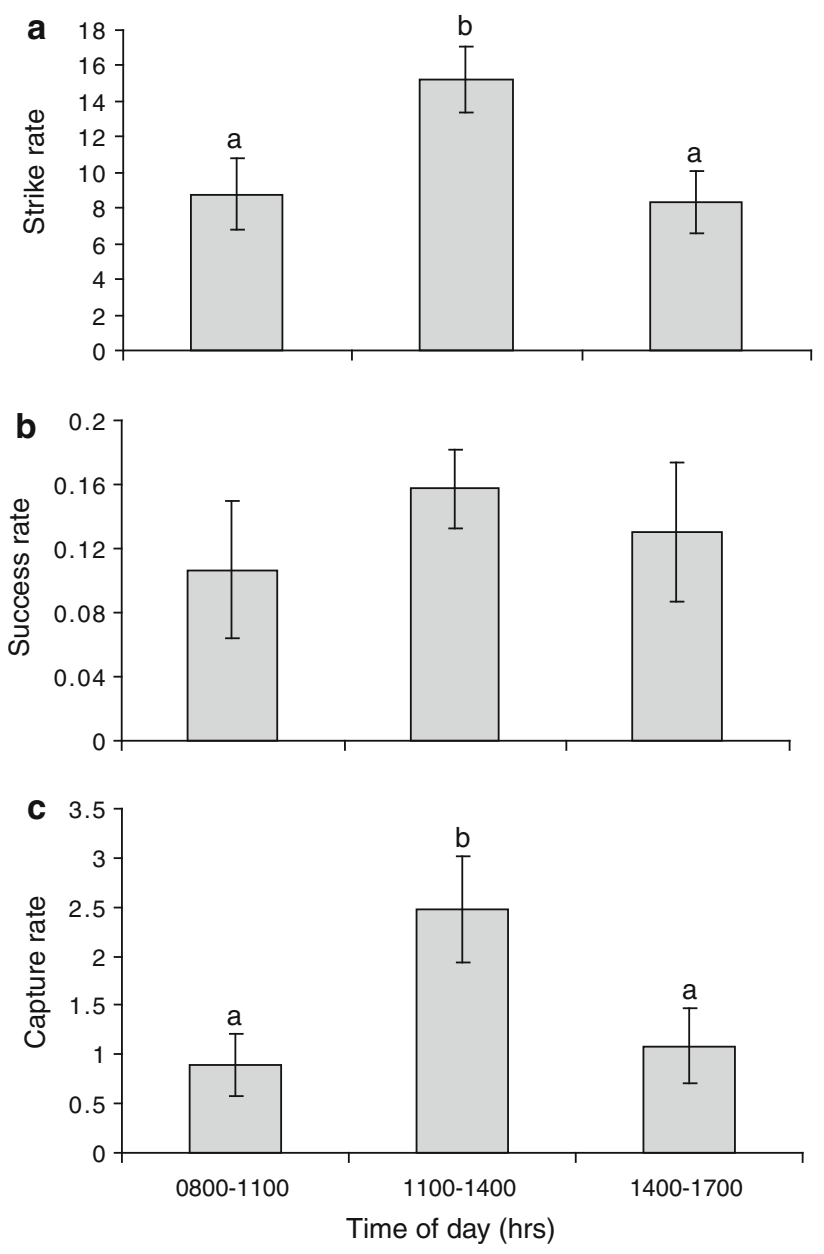

Fig. 2 The effect of diurnal time period (0800-1059 hours, $n=6$; 1100-1359 hours, $n=6$; $1400-1659$ hours, $n=8$ ) on Pseudochromis fuscus: a strike rate b success per strike c total number of juvenile fishes captured per hour. Error bars are standard error. Letters denote Tukey's HSD grouping $(p<0.05)$

fish striking at small prey fish during the recruitment period on average 10.52 times $^{-1}( \pm 1.24 \mathrm{SE})$. There was no difference in strike success among size classes, with success averaging $13.1 \%\left(F_{2,17}=3.41, p=0.06\right.$; Fig. $\left.5 b\right)$. Large individuals had a significantly higher consumption of juvenile fish than small individuals $\left(2.36\right.$ fish $^{-1}, 0.49$ fish $\mathrm{h}^{-1}$, respectively), with medium individuals being a non-significant and intermediate between the two $\left(1.18\right.$ fish $\mathrm{h}^{-1}$; $F_{2,17}=6.35, p=0.01$; Fig. $5 \mathrm{c}$ ).

\section{Digestion rate}

Regression analysis revealed a significant relationship between time (h) and digestion state of consumed recruit damselfishes (digestion state $=1.56+0.69$ time, $r^{2}=$ $0.5, p<0.05$ ), with complete digestion in $\sim 6.4 \mathrm{~h}$. Recruit fishes were in the states of major and advanced digestion after only $2-4 \mathrm{~h}$.
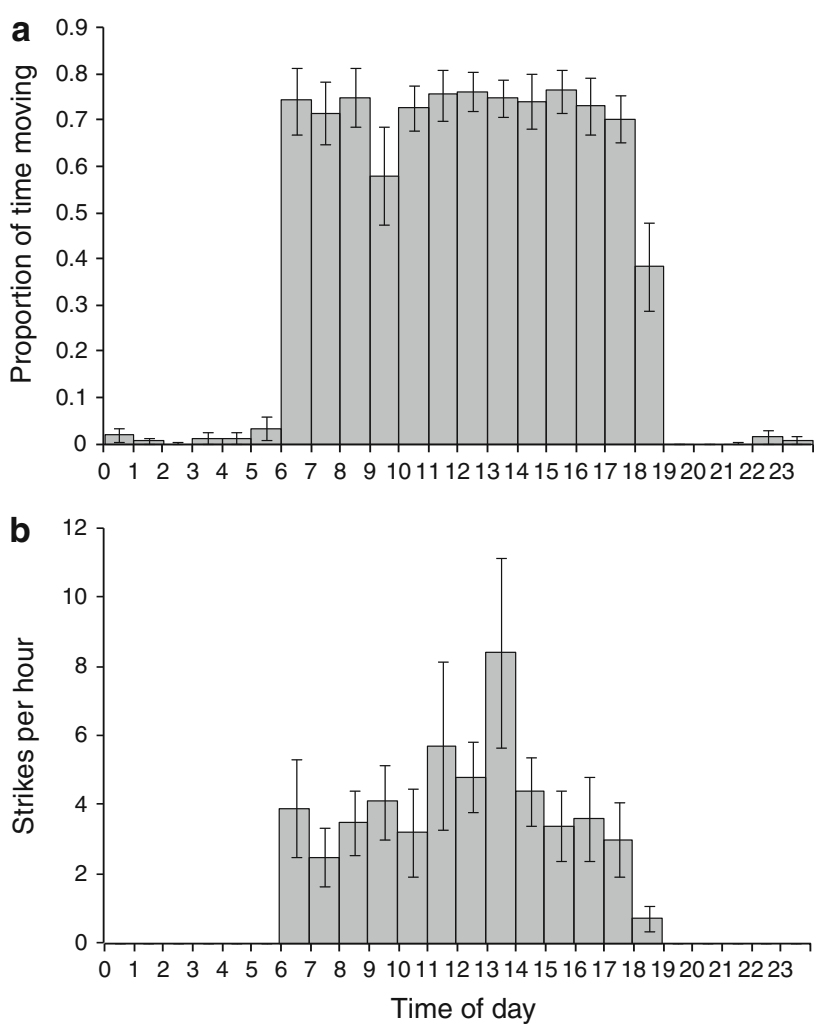

Fig. 3 Mean diel activity patterns for Pseudochromis fuscus housed in aquaria with visual and olfactory access to prey cues. a Proportion of time per hour spent moving; b number of strikes per hour. Error bars are standard errors

Daily consumption of juvenile fish populations

The 20 P. fuscus observed during the recruitment period made a total of 216 strikes at fishes of which 30 were successful, giving an overall $13.9 \%$ strike success rate $(13.1 \% \pm 0.02 \mathrm{SE}$ calculated as a mean of individual success rates). The information from the field and laboratory studies of strike rates facilitates the calculation of preliminary estimates of overall daily consumption rates. Laboratory studies showed that while all individuals were actively swimming during daylight hours $(13 \mathrm{~h})$, they struck at prey in the laboratory for between 4 and $13 \mathrm{~h}$ in a 24-h period (mean $9.7 \mathrm{~h}, n=10 \mathrm{fish}$ ). Also, observations in the field showed that strike success was highest around midday. If $13 \mathrm{~h}$ of foraging is assumed, then the overall capture of fish is estimated to be 16.4 juveniles/P. fuscus/ day $( \pm 3.4 \mathrm{CL})$. Of this, the ambush feeding mode accounted for 11.2 fishes $( \pm 2.8 \mathrm{CL}, n=20)$, and the pursuit mode accounted for 5.2 fishes $( \pm 1.8 \mathrm{CL}, n=20)$. If a minimum of $4 \mathrm{~h}$ of foraging is assumed per day, then consumption is estimated as 8.5 juveniles/P. fuscus/day $( \pm 1.9 \mathrm{CL})$, while if we assume a mean foraging activity of $9.7 \mathrm{~h}$, then overall capture rate per day is 14.04 juveniles P. fuscus $^{-1}$ day $^{-1}$ ( $\left.\pm 2.7 \mathrm{CL}\right)$. 

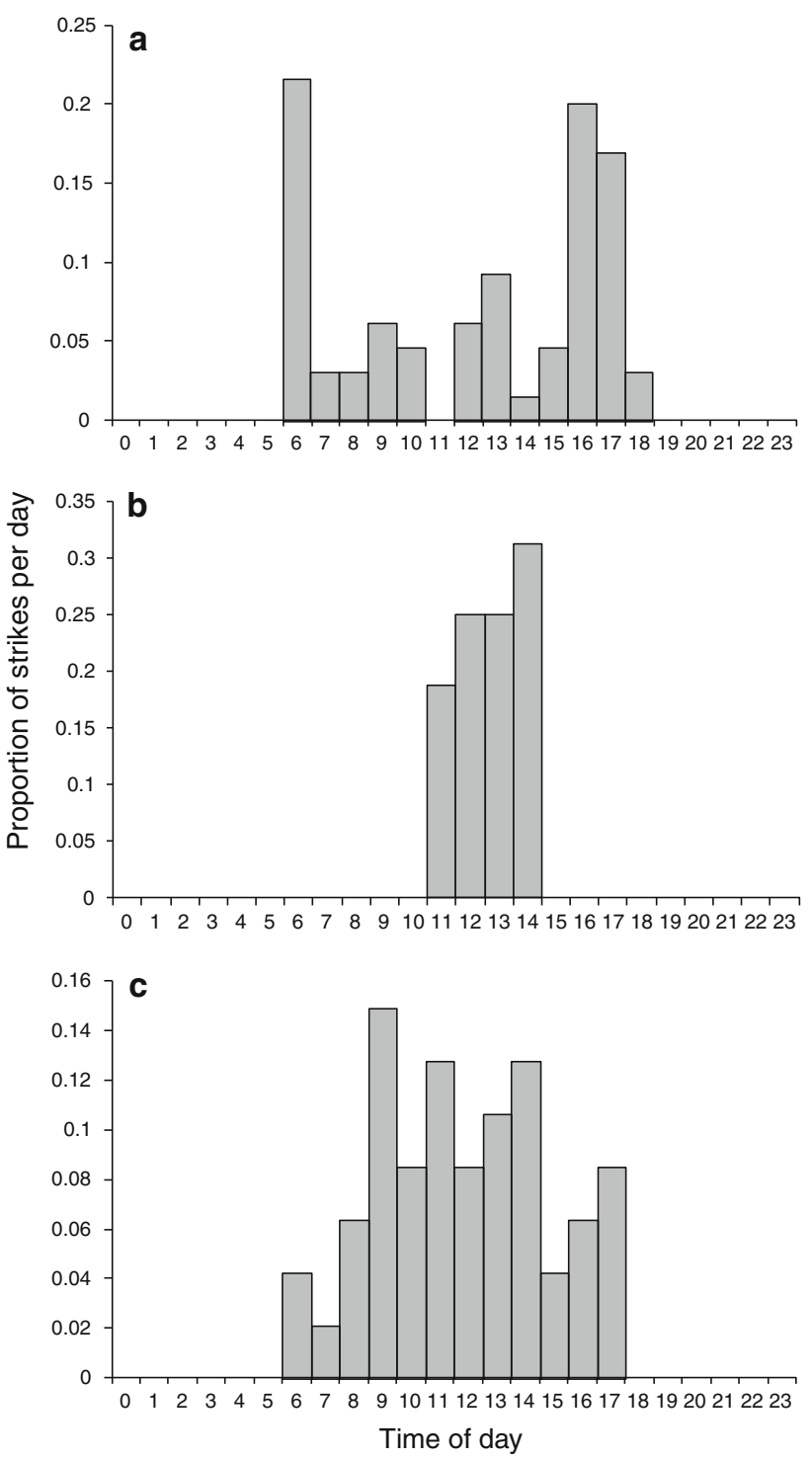

Fig. 4 Diel activity patterns of three (a, b, c) Pseudochromis fuscus housed in aquaria illustrating individual variability in the distribution of strikes at prey over a $24-\mathrm{h}$ period

A significant relationship was found between hourly consumption of juveniles and size class. Large individuals had a higher consumption of juveniles per hour than their small counterparts (Fig. 2). This resulted in an hourly consumption of 0.49 juveniles \pm 0.22 SE for small $P$. fuscus (6.33 juveniles day $\left.{ }^{-1} \pm 7.3 \mathrm{CL}, n=6\right), 1.18 \pm 0.49$ $\mathrm{SE}$ for medium individuals (15.39 day ${ }^{-1} \pm 16.4 \mathrm{CL}$, $n=6)$ and $2.36 \pm 0.38$ SE for large individuals (30.62 day $\left.{ }^{-1} \pm 13.6 \mathrm{CL}, n=8\right)$.

\section{Discussion}

While many studies state that mortality is high for reef fishes immediately after settlement (e.g. Hixon 1991; Carr
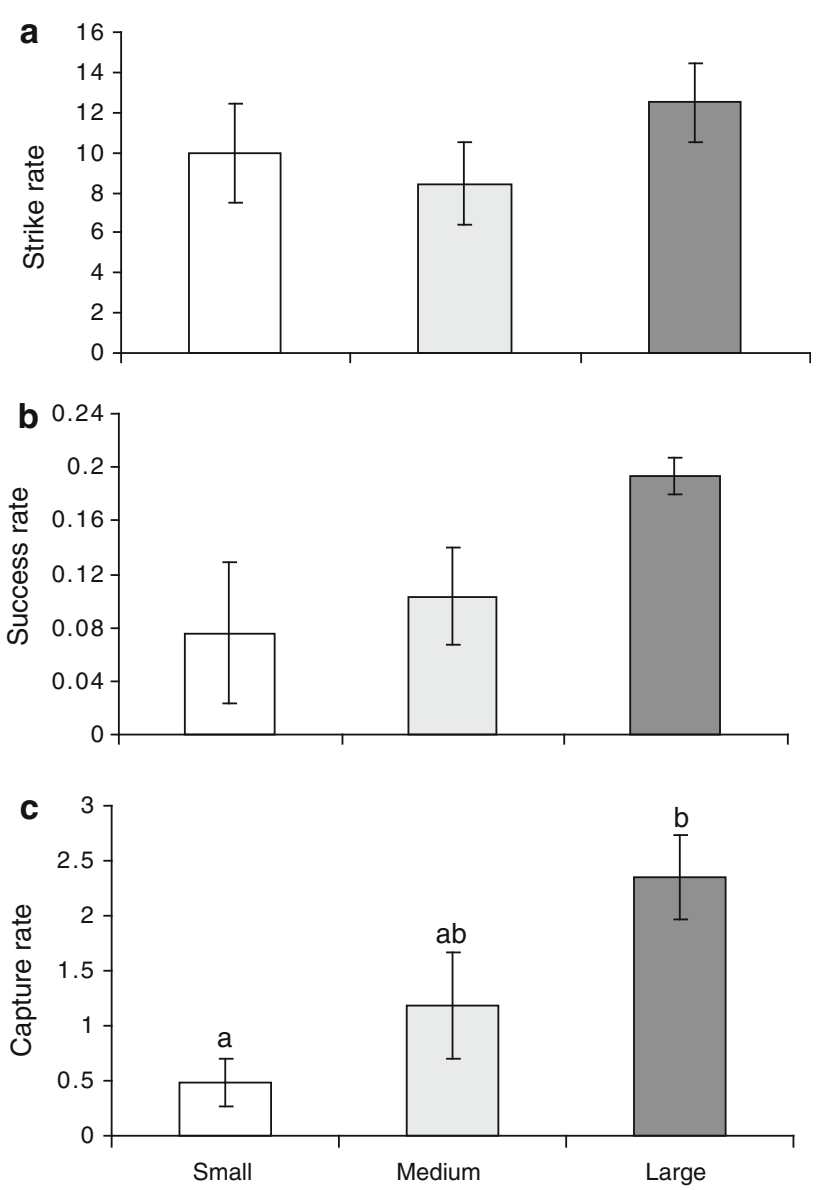

Fig. 5 The effect of Pseudochromis fuscus size (small, $n=6$; medium, $n=6$; large, $n=8$ ) on: a strike rate $\mathbf{b}$ success per strike c total number of juvenile fishes captured per hour. Error bars are standard error. Letters denote Tukey's HSD grouping $(p<0.05)$

and Hixon 1995; Caley 1998; Almany and Webster 2006), relatively few studies have quantified predation rates from the point of view of the predators involved (for some exceptions, see Sweatman 1984; Connell 1998; Holbrook and Schmitt 2002; Beukers-Stewart and Jones 2004; Côté and Maljković 2010; Green et al. 2011). Estimates of recruit mortality within the first $48 \mathrm{~h}$ on the reef vary widely, from total loss to no loss, with one study estimating the average loss at 56\% (Almany and Webster 2006). The present study shows that Pseudochromis fuscus is a small active predator that consumes a high number of juvenile fishes when they are available and may be responsible for much of the mortality in the early juvenile life phase where it occurs. Field observations revealed very high capture rates, which indicate that this species may have a major influence on the composition of the fish assemblage that develops within its habitat.

The rates of prey removal by $P$. fuscus exceed previous estimate of prey removal rates by other coral reef predators that consume small and juvenile fishes. Most information 
on the potential impact of various predator species comes from gut content analyses (e.g. Connell 1998; St John 1999, 2001). Some studies couple this information with gut evacuation rates to obtain estimates of potential capture and consumption rates (e.g. Martin 1994; Beukers-Stewart and Jones 2004). This method was used on two rock cod species, known to be common predators of small and juvenile reef fishes, Cephalopholis boenak $\left(0.41\right.$ fish $\left.^{-1}\right)$ and C. cyanostigma (0.63 fish $\mathrm{d}^{-1}$ ) (Beukers-Stewart and Jones 2004). Few studies have used focal animal observations in the field to investigate the predatory ecology of small predators on coral reefs. Sweatman (1984) followed the lizardfish, Synodus variegatus, at the same location as the present study. This ambush predator struck at prey on average 1.7 times $\mathrm{h}^{-1}$, with a 0.14 fish $\mathrm{h}^{-1}$ capture rate. Overall $11 \%$ of feeding strikes were successful with its ambush feeding mode. This equated to an average consumption of 1.8 fish $\mathrm{d}^{-1}$. Côté and Maljković (2010) and Green et al. (2011) followed an invasive population of Indo-Pacific lionfish, mainly Pterois volitans, in the Bahamas in unmanipulated field conditions. This predator was observed to strike at 1.98 juvenile or adult prey fishes per hour and had a very high success rate of $72 \%$. This resulted in predation rates of 1.44 captures $h^{-1}$ and an estimated daily consumption of approximately 13 fishes over a 12-h day.

The capture rates found for $P$. fuscus in the present study are among the highest recorded to date and are similar to the astonishingly high rates found for lionfish in the Bahamas (Côté and Maljković 2010). P. fuscus employed two distinct feeding modes that had very different success rates: an ambush feeding strategy that was successful $27.8 \%$ of the time, and a pursuit mode that yielded a $6.9 \%$ success rate. Overall, the success rate was $13.9 \%$. The relatively high feeding success and high strike rate combined to an average daily consumption of 16.4 juvenile fishes per $P$. fuscus over a 13-h day, or conservatively, 8.5 juveniles per $P$. fuscus over a 4-h day. This is a considerably higher estimated impact than other naturally occurring predators of juvenile fishes, with an individual $P$. fuscus being potentially responsible for 5-9 times greater juvenile mortality than a lizardfish, and over 13-20 times greater mortality than individuals of the two rock cods.

The high consumption rate in P. fuscus may be facilitated by high rates of digestion, high strike rate and the small size of prey consumed. Estimates of digestion times of small recruits by P. fuscus $(6.4 \mathrm{~h})$ are twice that of Cephalopholis boenak, whose digestion rate was assessed using similar methods ( $\sim 12 \mathrm{~h}$, Beukers-Stewart and Jones 2004). While the overall strike success rate for $P$. fuscus was not much higher than the lizardfish (13.9 vs $11 \%)$, the strike rate (successful or otherwise) was 6 times higher (10.5 vs 1.7). Lizardfish were also found to consume prey that were $36 \%$ as large as themselves, with each small fish captured representing $6 \%$ of their body weight (Sweatman 1984). In comparison, P. fuscus selects for small recruits ( $\sim 12.7 \mathrm{~mm} \mathrm{SL}$; Holmes and McCormick 2010), which represent only $\sim 1.3 \%$ of the predator's body mass, and this may facilitate their higher prey intake.

The extremely high consumption rates for $P$. fuscus compared to other predators for which estimates are available are surprising and may be due to the relatively high energy intake that is necessary to fuel a fast metabolism. Physiological rates (metabolism) scale with a $3 / 4$ power to body weight (Kleiber's law, Willmer et al. 2000), so P. fuscus should have a much higher metabolism than the lizardfish or the two rock cods due to its smaller body mass. Comparing large individuals across species, but limiting them to a size that may still eat recruits, would mean that $P$. fuscus (at $82 \mathrm{~mm}$ TL) would have approximately 5 times the metabolism of $S$. variegatus (at $200 \mathrm{~mm}$ TL), 9 times that of C. boenak (at $200 \mathrm{~mm} \mathrm{TL}$ ) and 10 times that of $C$. cyanostigma (at $200 \mathrm{~mm}$ TL). Preliminary estimates of metabolism suggest that they do indeed have fast metabolic rates $\left(4.3 \mathrm{~g}\right.$ fish at $29^{\circ} \mathrm{C}$ minimum metabolic rate $170 \mathrm{mgO}_{2} \mathrm{~kg}^{-1} \mathrm{~h}^{-1}$, maximum $660 \mathrm{mgO}_{2} \mathrm{~kg}^{-1} \mathrm{~h}^{-1}$ ), which is far higher than the estimate of $84 \mathrm{mgO}_{2} \mathrm{~kg}^{-1}$ $\mathrm{h}^{-1}$ for a $340 \mathrm{~g}$ lionfish (Côté and Maljković 2010). Applying similar calculations to those used by Côté and Maljković (2010) yields consumption estimates necessary meet metabolic demands in keeping with our field observations: 0.6 recruits $\mathrm{d}^{-1}$ (when resting) to 12 recruits $\mathrm{d}^{-1}$ (when active) (Electronic Supplemental Material, ESM Appendix 1). These estimates reinforce the potential influence of small predators, such as P. fuscus, on the recruit assemblage.

Estimating the direct effect of predators on a prey population is difficult due to the rapid and sporadic nature of predation events. All methods of collecting information about the influence of predators on their prey are inherently biased to varying degrees. Estimates based on the combinations of variables such as gut contents, digestive rates, predator and prey densities often do not account for the error estimates associated with each component, making the confidence around estimates of consumption unclear. Moreover, fishes are often collected for gut contents in a non-random way (e.g. spearfishing and linefishing), hampering interpretation. Direct observations of predation minimise the need to combine variances; however, they assume that individuals observed are representative of the target population; an assumption common to all methods. While attempts were made in the present study to randomly choose focal $P$. fuscus by undertaking intensive searches, the sample may have been biased towards hungry individuals if gut fullness was negatively related to activity levels. This may skew observational data to individuals that 
are bolder and more active (e.g. Wilson et al. 1993), who tend to have higher bite rates (McCormick and Meekan 2010). Côté and Maljković (2010) found that feeding attempts were an order of magnitude lower for stationary lionfish than active individuals, emphasising this potential problem. Our estimates of mortality were somewhat improved by examining individual variability in activity and strike rate over the diel cycle, but this can only be undertaken in the controlled and artificial environment of a laboratory. In concert, despite the potential biases in sampling, our most conservative estimates based on the most inactive fish (who struck at prey in only 4 out of $24 \mathrm{~h}$ ) still suggest that $P$. fuscus may have a substantial impact on its prey assemblage $\left(8.5\right.$ juveniles $\left.\mathrm{d}^{-1}\right)$.

$P$. fuscus is an important predator with a strong influence on the community of settling fishes in the habitat it occupies. Not only is it responsible for an extremely high level of juvenile mortality but it is also highly selective. Laboratory and field experiments have shown that $P$. fuscus selects the largest recruits immediately after settlement, when juveniles are largely naive to reef-based predators (McCormick and Meekan 2007; Holmes and McCormick 2010). This strong and selective filter on recruit phenotypes differentially removes individuals that have grown fastest in a cohort because in tropical fishes, these fish tend to be the ones that settle largest (e.g. McCormick 1994). Phenotypic selection by predators can dramatically alter the relationships between pre- and post-settlement growth histories and the costs and benefits that early life history imposes on post-settlement life (McCormick and Hoey 2004; Hamilton et al. 2008; McCormick and Gagliano 2009; Grorud-Colvert and Sponaugle 2011). Given the gape limit and size preference of $P$. fuscus, small fish with a typical damselfish growth trajectory are only susceptible to this important mortality agent for $\sim 14$ days. While this is a short time in the life of a small fish that may have a longevity greater than 15 years (Choat and Robertson 2002), the intensity of mortality and selection means that active mesopredators have the ability to dramatically alter the size of cohorts among locations and through time depending upon their densities and feeding activity. At this life stage, small changes in the proportion of individuals surviving can lead to major alterations to the numbers reaching later life stages (Houde 1989).

In conclusion, the high consumption rate of juveniles fishes during the austral summer suggests that $P$. fuscus has the potential to be an important influence on the composition of fishes in coral reef sites it inhabits through targeted predation on recruit fishes. It is unclear how this potential influence on the development of the juvenile fish assemblage is affected by other predators that may compete with P. fuscus. Stallings (2008) has recently shown that intermediate predators can have strong effects on small prey through the behavioural modification of small predators. Most studies that examine predators focus on larger, more commercially important species, such as coral trouts (Serranidae) and snappers (Lutjanidae). While these are no doubt important predators, the current study highlights that smaller predators, such as $P$. fuscus, should not be overlooked. Climate change is predicted to reduce reef topography (Munday et al. 2008) and therefore likely to not just influence shelter sites for prey, but also for smaller predators, altering the fundamental interactions between predators and prey at a crucial life stage. The more we understand about these small, highly abundant predators and their role in determining species composition of communities and energy flow, the better we will be able to predict their response to the environmental changes forecast.

Acknowledgments We thank Susannah Leahy for field assistance and the staff at the Lizard Island Research Station for logistic support. Hwan-Jin Yoon provided some statistical advice, and Gerald Feeney, Belle Lönnstedt and Coco Larcom commented on drafts of the manuscript. We also thank Darren Johnson and Bryce BeukersStewart for their excellent comments on the initial version of the manuscript. Research was supported by the Australian Research Council Centre of Excellence for Coral Reef Studies and an Australian Research Council Discovery grant. Research was conducted under permits from the Great Barrier Reef Marine Park Authority and in accordance with the JCU Animal Ethics guidelines.

\section{References}

Almany GR (2004) Differential effects of habitat complexity, predators and competitors on abundance of juvenile and adult coral reef fishes. Oecologia 141:105-113

Almany GR, Webster MS (2006) The predation gauntlet: early postsettlement mortality in coral-reef fishes. Coral Reefs 25:19-22

Almany GR, Peacock LF, Syms C, McCormick MI, Jones GP (2007) Predators target rare prey species in coral-reef fish assemblages. Oecologia 152:751-761

Berger KM, Gese EM (2007) Does interference competition with wolves limit the distribution and abundance of coyotes? J Anim Ecol 76:1075-1085

Beukers J, Jones GP (1997) Habitat complexity modifies the impact of piscivores on a coral reef fish population. Oecologia 114:50-59

Beukers-Stewart BD, Jones GP (2004) The influence of prey abundance on the feeding ecology of two piscivorous species of coral reef fish. J Exp Mar Biol Ecol 299:155-184

Beukers-Stewart BD, Beukers-Stewart JS, Jones GP (2011) Behavioural and developmental responses of predatory coral reef fish to variation in the abundance of prey. Coral Reefs 30:855-864

Caley MJ (1998) Age-specific mortality rates in reef fishes: evidence and implications. Aust J Ecol 23:241-245

Carr MH, Hixon MA (1995) Predation effects on early postsettlement survivorship of coral reef fishes. Mar Ecol Prog Ser $124: 31-42$

Choat JH, Robertson DR (2002) Age-based studies. In: Sale PF (ed) Coral reef fishes: dynamic and diversity in a complex ecosystem. Elsevier, San Diego, pp 57-80 
Connell SD (1998) Patterns of pisciviory by resident predatory reef fish at One Tree Reef, Great Barrier Reef. Mar Freshw Res 49:25-30

Côté IM, Maljković A (2010) Predation rates of Indo-Pacific lionfish on Bahamian coral reefs. Mar Ecol Prog Ser 404:219-225

Doherty PJ, Dufour V, Galzin R, Hixon MA, Meekan MG, Planes S (2004) High mortality during settlement is a population bottleneck for a tropical surgeonfish. Ecology 85:2422-2428

Domenici P, Blake RW (1997) The kinematics and performance of fish fast-start swimming. J Exp Biol 200:1165-1178

Elmhagen B, Rushton SP (2007) Trophic control of mesopredators in terrestrial ecosystems: top-down or bottom-up? Ecol Lett 10:197-206

Estes JA, Terborgh J, Brashares JS, Power ME, Berger J, Bond WJ, Carpenter SR, Essington TE, Holt RD, Jackson JBC, Marquis RJ, Oksanen L, Oksanen T, Paine RT, Pikitch EK, Ripple WJ, Sandin SA, Scheffer M, Schoener TW, Shurin JB, Sinclair ARE, Soule ME, Virtanen R, Wardle DA (2011) Trophic downgrading of planet Earth. Science 333:301-306

Finke DL, Denno RF (2004) Predator diversity dampens trophic cascades. Nature 429:407-410

Frank KT, Petrie B, Choi JS, Leggett WC (2005) Trophic cascades in a formerly cod-dominated ecosystem. Science 308:1621

Fuiman LA, Rose KA, Cowan JH, Smith EP (2006) Survival skills required for predator evasion by fish larvae and their relation to laboratory measures of performance. Anim Behav 71:1389-1399

Gagliano M, McCormick MI, Meekan MG (2007) Survival against the odds: ontogenetic changes in selective pressure mediate growth-mortality trade-offs in a marine fish. Proc Roy Soc Lond B 247:1575-1582

Gill AC (2004) Revision of the Indo-Pacific dottyback fish subfamily Pseudochrominae. Smithiana Monograph 1. South African Inst Aquat Biodivers, p 213

Green SJ, Akins JL, Côté IM (2011) Foraging behaviour and prey consumption in the Indo-Pacific lionfish on Bahamian coral reefs. Mar Ecol Prog Ser 433:159-167

Grorud-Colvert K, Sponaugle S (2011) Variability in water temperature affects trait-mediated survival of a newly settled coral reef fish. Oecologia 165:675-686

Hamilton SL, Regetz J, Warner RR (2008) Postsettlement survival linked to larval life in a marine fish. Proc Natl Acad Sci USA 105:1561-1566

Hixon MA (1991) Predation as a process structuring coral reef fish communities. In: Sale PF (ed) The ecology of fishes on coral reefs. Academic Press, San Diego, pp 475-507

Holbrook SJ, Schmitt RJ (2002) Competition for shelter space causes density-dependent predation mortality in damselfishes. Ecology 83:2855-2868

Holmes TH, McCormick MI (2009) Influence of prey body characteristics and performance on predator selection. Oecologia 159:401-413

Holmes TH, McCormick MI (2010) Size-selectivity of predatory reef fish on juvenile prey. Mar Ecol Prog Ser 399:273-283

Houde ED (1989) Subtleties and episodes in the early life of fishes. J Fish Biol 35:29-38

Johnson DW, Hixon MA (2010) Ontogenetic and spatial variation in size-selective mortality of a marine fish. J Evol Biol 23:724-737

Johnson DW, Hixon MA (2011) Sexual and lifetime selection on body size in a marine fish: the importance of life-history tradeoffs. J Evol Biol 24:1653-1663

Lima SL, Dill LM (1990) Behavioural decisions made under risk of predation: a review and prospectus. Can J Zool 68:619-640

Martin J (1994) Predation on juvenile coral reef fish at Lizard Island, northern Great Barrier Reef: an ecological and behavioural study. BSc Honours thesis, James Cook University, 67 pp
McCormick MI (1994) Variability in age and size at settlement of the tropical goatfish Upeneus tragula (Mullidae) in the northern Great Barrier Reef lagoon. Mar Ecol Prog Ser 103:1-15

McCormick MI, Gagliano M (2009) Carry-over effects-the importance of a good start. Proc 11th Int Coral Reef Symp: 305-310

McCormick MI, Hoey AS (2004) Larval growth history determines juvenile growth and survival in a tropical marine fish. Oikos 106:225-242

McCormick MI, Meekan MG (2007) Social facilitation of selective mortality. Ecology 88:1562-1570

McCormick MI, Meekan MG (2010) The importance of attitude: the influence of behaviour on survival at an ontogenetic boundary. Mar Ecol Prog Ser 407:173-185

Messmer V, van Herwerden L, Munday PL, Jones GP (2005) Phylogeography of colour polymorphism in the coral reef fish Pseudochromis fuscus, from Papua New Guinea and the Great Barrier Reef. Coral Reefs 24:392-402

Mukherjee S, Zelcer M, Kotler BM (2009) Patch use in time and space for a meso-predator in a risky world. Oecologia 159:661-668

Munday PL, Eyre PJ, Jones GP (2003) Ecological mechanisms for a coexistence of colour polymorphism in a coral-reef fish: an experimental evaluation. Oecologia 137:519-526

Munday PL, Jones GP, Pratchett MS, Williams AJ (2008) Climate change and the future for coral reef fishes. Fish Fish 9:261-285

Myers RA, Baum JK, Shepherd TD, Powers SP, Peterson CH (2007) Cascading effects of the loss of apex predatory sharks from a coastal ocean. Science 315:1846

Navarrete SA, Berlow EL (2006) Variable interaction strengths stabilize marine community structure. Ecol Lett 9:526-536

O'Steen S, Cullum AJ, Bennett AF (2002) Rapid evolution of escape ability in Trinidadian guppies (Poecillia reticulata). Evolution 56:776-784

St John J (1999) Ontogenetic changes in the diet of the coral reef grouper Plectropomus leopardus (Serranidae): patterns in taxa, size and habitat of prey. Mar Ecol Prog Ser 180:233-246

St John J (2001) Temporal variation in the diet of a coral reef piscivore (Pisces: Serranidae) was not seasonal. Coral Reefs 20:163-170

Stallings CD (2008) Indirect effects of an exploited predator on recruitment of coral-reef fishes. Ecology 89:2090-2095

Stallings CD (2009) Predator identity and recruitment of coral-reef fishes: indirect effects of fishing. Mar Ecol Prog Ser 383:251-259

Stewart BD, Jones GP (2001) Associations between the abundance of piscivorous fishes and their prey on coral reefs: implications for prey-fish mortality. Mar Biol 138:383-397

Strobbe F, McPeek MA, De Block M, Stoks R (2011) Fish predation selects for reduced foraging activity. Behav Ecol Sociobiol 65:241-247

Sweatman HPA (1984) A field study of the predatory behavior and feeding rate of a piscivorous coral reef fish the lizardfish Synodus englemani. Copeia 1:187-194

Verdolin JL (2006) Meta-analysis of foraging and predation risk trade-offs in terrestrial systems. Behav Ecol Sociobiol 60:457-464

White JW, Samhouri JF, Stier AC, Wormald CL, Hamilton SL, Sandin SA (2010) Synthesizing mechanisms of density dependence in reef fishes: behavior, habitat configuration, and observational scale. Ecology 91:1949-1961

Willmer P, Stine G, Johnson I (2000) Environmental physiology of animals. Blackwell Science Ltd, London

Wilson DS, Coleman K, Clark AB, Biederman L (1993) Shy-bold continuum in pumpkinseed sunfish (Leopomis gibbosus): an ecological study of a psychological trait. J Comp Psychol 107:250-260 